\title{
sciendo
}

Research Article

C 2019 Thatsanee Ngoensuk and Chantana Viriyavejakul. This is an open access article licensed under the Creative Commons Attribution-NonCommercial-NoDerivs License (http://creativecommons.org/licenses/by-nc-nd/3.0/).

\section{A Privacy Violation Behaviors Preventive System in Using Social Media by Graduate Students of King Mongkut's Institute of Technology Ladkrabang}

Thatsanee Ngoensuk

\author{
Ph.D.Candidate, Department of Industrial Education, \\ Faculty of Industrial Education and Technology, \\ King Mongkut's Institute of Technology Ladkrabang, Bangkok, Thailand \\ Chantana Viriyavejakul
}

Associate Professor Dr., Department of Industrial Education, Faculty of Industrial Education and Technology, King Mongkut's Institute of Technology Ladkrabang, Bangkok, Thailand

Doi: $10.2478 / \mathrm{mjss}-2019-0056$

\begin{abstract}
The purpose of this research was to create, test and develop a model for developing a system to protect personal rights violations in using social media, Integrated learning styles using deductive teaching methods and the use of case studies to promote knowledge in developing a model for developing a system to protect personal rights violations in the use of social media of graduate students at King Mongkut Institute of Technology at Ladkrabang. The sample group used to develop the protection system model is a legal expert, 7 people, namely, graduate students of King Mongkut Institute of Technology Ladkrabang, 20 people. The tools used in this research are interview with legal experts and instructors, Knowledge measurement form, Online teaching and learning management system on privacy violation behavior in the use of social media Satisfaction questionnaire for learning styles and Assessment form for certification of integrated teaching and learning styles. The results from the test scores of the pre-school and post-test scores of the sample group showed that the post-test scores had an average score higher than before (before 10.80 and 13.71). In addition, it was found that the post-test scores had a standard deviation less than the test scores before learning (after learning is 1.29 and before 3.70), indicating that the post-test scores were higher than the previous test scores. Therefore, it can be concluded that the sample group when learning through the learning style resulted in higher average student scores.
\end{abstract}

Keywords: violation of personal rights, readiness for self-learning, protection system development

\section{Introduction}

Essentially, the rights and freedom of using the online media available to us are not different from the rights and freedom of other media because it is considered freedom of expression through the media. In fact, this right includes the freedom to hold thoughts without interference and to seek, receive and distribute news and opinions, regardless of any way and regardless of boundaries. When liberty has occurred, it is certain that the boundaries of each individual's freedom will collide and overlap; in some cases, it becomes a violation of individual rights. Especially in the social networking world where it seems as in the boundaries of freedom of expression there will be so much that sometimes there may be too much as well. The need for supervision, supervisory and monitor usage including the standard of behavior, expression, and usage make it necessary in today's online society. In the aspect of respecting the right to privacy, actually, it is about the basic 
rights of people who have been protected since the start of the Constitution. The rights of family members, honor, reputation and personal well-being are protected, including amending the news that is widely used by any message or image in any way to the public which is a violation as provided by law Office of the council of state (2007) or affect the rights of a person in the family, honor, reputation or personal well-being will not be done, except for cases that are beneficial to the public.

Although the development of technology in various forms will produce good results, on the other hand, if misuse of information is used, it may cause damage as well. Especially in the cases of personal information it is like a double-edged sword. If users lack morality, ethics, common sense, lack of legal knowledge, knowing respect for the rights of others or being careful in using, these online communities will be "a dangerous society" and thus be a dark side of society. Therefore, everyone must be aware of Privacy as a fundamental right of human beings. In modern society, almost every country gives importance to this and can be seen from the certification of such principles in the Constitution or even if some countries do not have direct recognition in the constitution, they have adopted a certification in specific laws.

Problems of privacy violations in the use of social media can have the form of committing an offense, such as bringing personal information that is published through social networks of other people, such as pictures, personal profiles and used without permission as well as sending messages or other information to disturb the privacy of online social network users. Even the uploading of video clips of other people's personal lives, recorded television programs that cause damage to others are also considered violations of the privacy rights of others through social networks.

The study of the development of a system to protect personal rights violations in the use of social media makes people aware of the causes of factors affecting the violation of personal rights in using social media online. In doing so, we will know the cause of behavior that should not be done. The user should have a regulatory system that takes care and checks each other. If users have ethical standards, good behavior has a code of conduct as both a messenger and a good messenger so that online society will become a great benefit to humanity. Recognizing the importance of the problem by supporting the concept, guidelines should be set for students to have knowledge about the law practices in the right way and make a readiness in terms of behavior in using social media online in the right way, in order to be a representative to disseminate knowledge and watch further.

\section{Literature Review}

The situation of online privacy violations in Thailand can be seen from the common characteristics of cases that are found which are the internet and online services, making personal information very important to modern people. It is felt that it can cause many problems in life from the heart to the loss of property and finances. The internet facilitates the collection and distribution of personal information much more easily than used to be. However, the issue of privacy is a difficult one to clearly define, with many nuances involved or a person realizing which action is a violation of privacy. Many individuals have different levels of feeling of being threatened with privacy (Monchai, 2002).

Initially, this situation can be classified according to 4 types of problems, namely violations of privacy of private business, which are mostly forwarded to other third parties, violations of privacy from government agencies that do not have sufficient personal information protection measures for the public, media that are not careful in presenting news and privacy violations between online users.

In summary, learning and innovation skills, the learning management which encourages students to "learn how to learn" is necessary to destroy the limitations of traditional classrooms. Teachers have changed their paradigm for learning management of enthusiastic learners and selflearners. The teacher acts as a consultant. Students can utilize technology as a tool to seek knowledge and create their work through participatory learning when passing a specific course, so that students will receive initiative and practical skills. Knowledge from experience can be created by one's self. 
When considering cases of privacy violations caused by the users themselves, it reflects the complexity of privacy. In one way, it seems that internet users are aware of the importance of personal information. Seen from the use of personal information as a tool to bully people who are not satisfied at the same time, the convenience of technology makes them search and allows the disseminating of personal information of others more easily who may be aware or not aware of privacy protection and the consequences that can possibly follow. (Thai Netizen Network: Privacy International: SAFEGUARD, 2013)

\section{Research Objectives}

- To study some factors affecting personal rights violation in using social media of graduate students, King Mongkut Institute of Technology at Ladkrabang

- To study the readiness for self-learning in using social media of graduate students. King Mongkut Institute of Technology at Ladkrabang

- To create, test and develop a system to prevent the occurrence of personal rights violations in the use of social media Self-learning Integrated learning styles using deductive teaching methods and the use of case studies to promote knowledge in the development of a model to protect the violation of personal rights in using social media among graduate students at King Mongkut Institute of Technology at Ladkrabang.

\section{Research Methods}

Population: The population in the study of opinions is legal experts. The population of the experimental model is graduate students, King Mongkut Institute of Technology at Ladkrabang and Population in the certification of the form of protection system development Legal teaching expert and experts in educational technology and communication. Sample group: The sample group used in the study of opinions is 7 people. The sample group used in the experiment was 20 graduate students of King Mongkut's Institute of Technology Ladkrabang and the sample group used in the study of opinions is 2 experts in teaching law and has experience in teaching law about human rights violations, computer laws and experts in educational technology and communication are derived from specific areas.

This research and development is divided into 3 steps according to the objectives of the research:

\subsection{Step 1: The study of some factors that affect personal rights violation in using social media of} graduate students at King Mongkut Institute of Technology at Ladkrabang.

To study the relationship between some factors affecting personal rights violation in using social media of graduate students at King Mongkut Institute of Technology at Ladkrabang including the characteristics of the population Self-efficacy and self-control on the violation of personal rights in using social media of graduate students, King Mongkut Institute of Technology at Ladkrabang with a sample group of graduate students, King Mongkut Institute of Technology at Ladkrabang, the first semester of academic year 2015, 400 people, which were derived from Multi-Stage Sampling using questionnaires. The statistics used for data analysis are frequencies, percentages, mean and standard deviation as well as testing the hypothesis with T-test, one-way analysis of variance, Oneway ANOVA. The hypothesis test found that different demographic characteristics have behavior in violation of personal rights in using social media that differ in age, gender, faculty, occupation and income. Self-efficacy knowledge and understanding about laws and legal penalties and overall privacy violations are significantly different as well as self-control on privacy violations in using social media. The disclosure of information and the behavior of personal rights violation in using social media is significantly different at the level of .05 . 


\subsection{Step 2: The study of the readiness for self-learning in using social media for graduate} students. King Mongkut Institute of Technology at Ladkrabang.

To study and compare the differences in the readiness of self-learning in using social media of students at Graduate Studies, King Mongkut Institute of Technology at Ladkrabang different classes, years of age and gender, the population used in this study are graduate students. King Mongkut Institute of Technology at Ladkrabang. The sample used in this study is the graduate students of King Mongkut Institute of Technology at Ladkrabang, the current students, 1st semester, academic year 2015, Year 1-6, enrolled in English for Graduate studies in the first semester of the academic year 2015, 20 students, including 12 first year students, 5 second year students, 3 students from 3-6 years and variables used in the study of independent variables, including graduate student characteristics King Mongkut Institute of Technology at Ladkrabang dependent variable, ie the level of opinion of readiness with e-learning Access to technology (technology access), online skills and relationships, motivation, online video and audio (Online Audio / Video), Internet Discussions and Importance to one's success.

Research tools: The creation of this research tool is an introduction to the evaluation of readiness for learning with e-learning. The study of the readiness of learners or those who will be trained via electronic systems by improving in Thai language (Watkins, Leigh and Triner, 2004) By measuring the level of readiness with e-learning, divided into 2 parts; with part 1 as information about respondents and part 2 as divided into 6 areas, namely technology access, relationship and skills, online skill and relationships, Motivation, visual and audio online (Online Audio / Video), Internet Discussions and Importance to one's success is a 5-level measure comment level with moderate 2 means as the opinion level with at least 3 means the opinion level with the least amount of 27 items taken to test with the experimental group to find the confidence value and submit the questionnaire to collect needed data. In this study By way of handing out questionnaires The sample group is all people filling out the questionnaire themselves (Questionnaire) then collecting the questionnaires received and checking the integrity for further analysis.

Quantitative data analysis from the questionnaire that has been returned By using SPSS computational computer program for data processing, part 1, data analysis from demographic survey (Demographic Characteristics) Of graduate students at King Mongkut Institute of Technology at Ladkrabang is used to calculate statistical values Frequency, standard deviation (SD), data analysis and mean (Mean). The data from the research set the criteria for translating the basic characteristics of the data by comparing the average values with the criteria. According to the concept of Best (Best, 1977). 5 levels (Rating Scale) As follows: Average 1.00 - 1.50 means the learner is ready to study with eLearning at the lowest level. Bring the average value to compare the readiness with the e-learning both 6 aspects and comparison between learners in different years different age ranges and different sexes. By using the statistical parametric analysis, the research found that Readiness for self-learning in using social media or with e-learning in all 6 aspects of graduate students King Mongkut Institute of Technology at Ladkrabang has no significant difference at the level of .05 . All 6 years of age are ready for self-learning and give priority from as many as possible to all 6 items in terms of access to technology (Technology Access), Online skill and relationships, Motivation, visual and audio online (Online Audio / Video), Internet Discussions and Importance to your success show that Graduate Students King Mongkut Institute of Technology at Ladkrabang recognize the benefits of self-learning in using social media or with e-learning and knowing the importance of accessing the most average technology.

4.3 Step 3: Creating a blended learning model using deductive teaching methods and using case studies to promote knowledge in preventing violations of personal rights in using social media for graduate students. King Mongkut Institute of Technology at Ladkrabang.

\subsubsection{Phase 1 research aims to create a blended learning model using the Instructional Design} Model, an updated system orientation model from Dick and Carey (2001) which is a form of design that has been recognized as being able to design teaching and learning that uses technology to support it well (Gustafon \& Branch, 2002). 


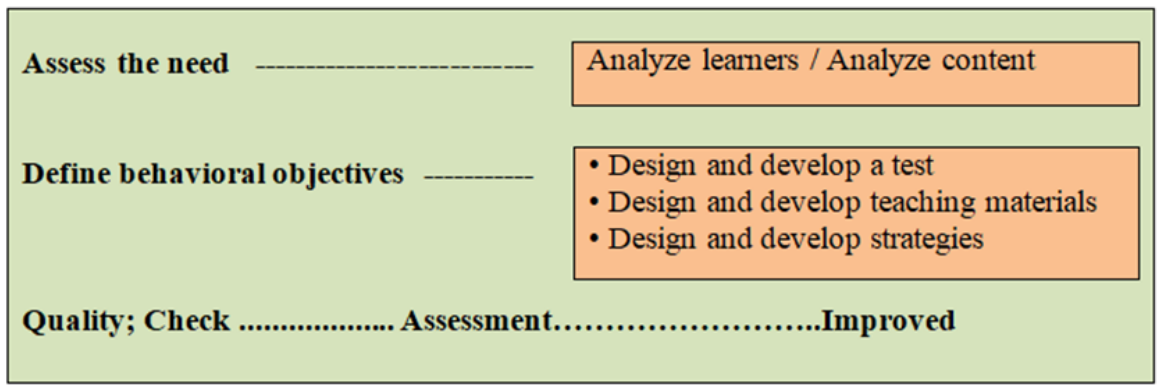

Figure 1. Improved teaching style design

Source: Dick and Carey (2001)

\subsubsection{Determine the purpose, teaching, education}

The researcher interviewed the instructor of the law on abuse. Human rights, public law 3 computer laws to determine the purpose of this design. By using a question without the structure by the three teachers has their opinions in determining the purpose of teaching that should encourage learners to have knowledge about the protection of privacy violations in the use of basic social media so they can be self-aware and aware of the importance of preventing the violation of personal rights in using social media

\subsubsection{Analysis of teaching}

Based on the interview of the course instructor, the law found that the content of the personal rights violation is as follows.

In the use of the same social media, it takes 1 time to complete the course ( 3 hours). There is a lecture method with video teaching. The teaching problems analyzed from the interview are as follows:

- The duration of teaching and learning is not enough to organize all teaching and learning activities.

- Teaching activities focus on developing knowledge and memory, not conducive to developing practical skills and attitudes.

\subsubsection{Studying the characteristics of learners}

According to the interview, 20 students enrolled in the English for Graduate studies in the first semester of the academic year 2015. The analysis from the interviews with students is as follows.

- Learners are aware of violations of privacy violations in the use of social media but do not know the penalty.

- Learners have a basis for reading information. The term can be interpreted by law.

- Most learners do not understand the importance of violating personal rights.

\subsubsection{Defining behavioral objectives}

From the analysis of the content about screening for violations of personal rights, it was found that the purpose of the study was divided into 3 parts according to Bloom's theory (Bloom, 1956), namely promoting knowledge about the law(Cognitive Domain), teaching the right ideals (Psychomotor Domain) and creating awareness of the importance of the researcher (Affective):

1. Students can explain the meaning of violations of privacy violations in the use of social media.

2. Learners can explain the behavior of expression that violates rights. 
3. Learners can explain the causes and factors that encourage abuse.

4. Learners can explain how to take preventive action.

5. Learners are aware of the importance of education in prevention of violations.

\subsubsection{Develop tools for measuring assessment}

The researcher took steps to develop the measurement tools as follows.

1. Perform content analysis to create a test / rubric assessment criteria in accordance with the behavioral objectives.

2. Testing of the content to 3 experts by the content validity test (ICO) by testing and evaluation criteria for all items with an average higher than 0.5 which is acceptable (luan Saiyot, 1996).

\subsubsection{Design teaching methods}

The researcher analyzed the conditions of teaching problems and the conditions of the learners from the interviews to get guidelines for the design so that the teaching style should be blended with learning that combines classroom activities and online learning activities together. Due to the high flexibility of teaching and learning (Bonk and Graham, 2006), this can help reduce the problem of insufficient teaching times. The combination of learning elements consists of 4 elements: 1) learning materials 2) learning management systems 3) communication 4) evaluation The teaching strategies that the researcher chooses to use in blended learning are a total of 2 types, based on consistency in the development of learners according to the objective behavior. Including the following:

1. Lecture teaching is a teaching style that aims to transfer knowledge to develop primary Buddhist characteristics with lectures conveying knowledge from the instructors who are experts in the course materials.

2. Deductive learning management is a process by which the instructors organizes learning, giving the learner the knowledge and understanding of the rules, theories, rules, facts or conclusions according to the objectives of the lesson and then apply the theory, principles, rules or any type of conclusions that can be used in a variety of situations or may be a feature for learners to find evidence to prove the theory of those rules or conclusions. This kind of learning management will help learners to be rational, not be naïve or gullible and have a deep understanding of those rules, conclusions, theories. This kind of teaching can be said to be a teaching from theory or rule to a detailed example.

3. Teaching by case study method (Case Study) is a teaching method which creates an attitude of awareness for learners. It is aimed at improving the student's mental characteristics and the case study activities will be held on the discussion board. Students will be grouped and assigned to do case studies where the instructor will post the case study in the room of each group. The questions in the case study will mainly focus on the understanding of the student's affiliation.

\subsubsection{Design and develop teaching materials from teaching strategies. The researcher therefore} has designed and selected 2 instructional media, including lessons on personal rights violations.

1. Learning materials (Courseware)

- Dividing the data into 4 parts (chunks), giving the length of the lesson, not working for more than 10 minutes each to reduce the student's memory burden.

- The content of the lesson uses images that are real images and images with in-depth details because the learners already have the same knowledge (Fleming, 1993).

- There is a self-assessment test at the end of the lesson so that students receive feedback from the lesson.

2. Test and questionnaire: The researcher has chosen to use the test and online questionnaire which is designed as it is easy to use, fast loading. (Surasak, 2009). 
4.3.2 Phase 2 An experimental blended learning model by using deductive teaching methods and using case studies to promote knowledge in preventing violations of personal rights in using social media of students.

The experimental plan in Phase 2 research is the One Group Pre-test and Post-test design. The number of people who spent 1 week in the trial Day tools used for data collection Namely the knowledge test about the criteria for assessing work on answering rubrics case studies and the questionnaire of satisfaction of learners towards learning statistics used in data analysis including descriptive statistics, mean and percentage.

4.3.3 Phase 3 Certification of blended learning styles using deductive teaching methods and the use of case studies to promote knowledge in the development of a model for the protection of personal rights violations in using social media and using case studies to promote knowledge A Privacy Violation Behaviors Preventive System in Using Social Media

The researcher created the evaluation form to certify the blended learning model and then bring it to a specialist group of 3 people who evaluated and certified the results. After that, adjustments were done to the format according to the expert's suggestions.

\section{Research Results}

Results from the test scores of the pre-school and post-test scores of the sample group showed that the post-test scores had an average score higher than before (before 10.80 and 13.71). In addition, it was found that the post-test scores had a standard deviation less than the test scores before learning (after learning is 1.29 and before 3.70), indicating that the post-test scores were higher than the previous test scores. Therefore, it can be concluded that the sample group when learning through the learning style resulted in higher average student scores.

Table 1: Test scores before and after study

\begin{tabular}{|l|c|c|}
\hline & Before studying & After study \\
\hline Average & 10.80 & 13.71 \\
\hline Standard deviation & 3.70 & 1.29 \\
\hline
\end{tabular}

Assessment of learning using using rubric assessment criteria. There are results as shown in Table 2:

Table 2: Results from the assessment of rubrics

\begin{tabular}{|l|c|}
\hline & Quality \\
\hline Linking with good things & Good \\
\hline Awareness of the importance of good abuse prevention & Good \\
\hline Interaction within the fair group & Suitable \\
\hline
\end{tabular}

From Table 2: The points linked to what is learned and the awareness of the importance of preventing violations of personal rights in using social media have a good level of quality and interactions within the group have a fair level of quality. It can be concluded that the work of the case study will help to connect the knowledge and things that have been learned well and studying the events that are of interest to the people from the study, will allow the learners to recognize the importance of preventing abuse as well.

Data from the satisfaction assessment form for various learning styles. There is a percentage of assessment as shown in Table 3, indicating that students are satisfied with the overall learning style at a good level. The topics that received the percentages were evaluated at a very good level, including methods of presentation, learning styles and multimedia learning materials. While other 
topics are good, demonstrating the opinions of most learners that teaching styles are suitable for teaching and learning.

Table 3: Percentage of satisfaction towards learning styles

\begin{tabular}{|l|c|c|c|c|c|}
\hline List & \multicolumn{4}{|c|}{ List of percentage of satisfaction } \\
\hline 1. Blended learning style & 5 & 4 & 3 & 2 & 1 \\
\hline 2. Method of presentation of learning styles & 36.5 & 50.00 & 13.5 & 0 & 0 \\
\hline 3. Multimedia learning materials & 50.0 & 40.7 & 9.3 & 0 & 0 \\
\hline 4. Interface and navigation of the learning website & 47.0 & 45.5 & 7.5 & 0 & 0 \\
\hline 5. Content of learning materials & 47.8 & 50.0 & 2.2 & 0 & 0 \\
\hline 6. Blended learning style & 22.0 & 65.5 & 12.5 & 0 & 0 \\
\hline
\end{tabular}

From the evaluation of the certification form by 7 experts, when considering the various items of the pattern, it was found that both the introduction and the format and most of the descriptions are appropriate for the certification level at the most appropriate level. By considering in the introduction section, so the purpose of the model And principles and reasons have the most appropriate certification level Percentage 80 and 60, respectively, and when considering the form and description, found that the diagram shows the pattern has the most appropriate certification level of 80 percent. The composition of the blended learning style in teaching media, learning management system and communication with the most appropriate certification level, accounted for 60 percent. The process of integrated learning style in the introduction. The step of teaching demonstration and evaluation has the highest appropriate certification level of 80 percent. In the list of blended learning styles it is appropriate to use to promote knowledge in preventing violations of personal rights in using social media and by the overall picture of the blended learning model and this can be used in practical situations and have the most appropriate certification level.

\section{Conclusion}

Discussion results Research - Self-efficacy, different levels of knowledge and understanding about laws are related to privacy violations in using social media by students who have limited knowledge and understanding. In case of these students of limited information, of course, there will be more violations of personal rights than students who have a lot of knowledge and understanding. In matters relating to laws and penalties caused by differences between individuals in the physical environment element and differences in emotions that influence individual differences which correspond to the research data (Laddavan, 2012) and will occur because of experience and familiarity with many applications. Therefore, the cause of behavior in violation of personal rights as well those which correspond to the interpersonal communication in the subject (Kitima, 2005) in their development of awareness to enhance human communication, individuals must check learning bounds and find more information correctly as well as they must change their perception and awareness at all times. Most people perceive things using old information, which is usually easy to do but incomplete and therefore they must check all information for clarity and the correctness of the conclusions about their recognition and self-control in using social media. The results of completed research found that most students revealed information about friends who publicly disclosed their own personal information in social media. Thus, there will be more violations of personal rights than only students who disclose information to friends and friends of friends and students who disclose specific information. This is something that needs to be developed to accurately disclose the truth. In the matter of recognition development, there will be consistency with the concept of (Teerapat, 2011). The research found that a person's readiness for self-learning in using social media or with e-learning was there in all 6 aspects of graduate students of King Mongkut Institute of Technology at Ladkrabang. There is no significant difference at the level of .05, all 6 years being ready for self-learning and getting priority from as many as possible sources of every item of all 6 aspects concerned.

Self-control in the use of social media, or the limited disclosure of different personal 
information is related to behavior in violation of personal rights in using social media. Research found that most of the students concerned revealed information about friends who publicly disclosed personal information not intended for other use. There will be more violations of personal rights than students who only disclose information to friends and friends of friends and students who unintentionally disclose specific information. This is something that needs to be developed to accurately describe the true situation in the matter of recognition development. This will be consistent with the concept of the purpose of communication that requires changes in behavior or actions of individuals, since copying actions and continuous actions, include natural actions that need to be understood together. These types of websites are not neutral media space, but have a very public and open nature depending on the settings of each user, which can be very different to the area of exchange of opinions or articles in newspapers, of which style is long writing. However, this does not mean that these websites, which are not neutral media, will not be required to have a code of ethics or social acceptability standard of use, as a code of ethics will lead to more credibility and that reliability must be measured from the content, not from the form of a reason like this, because the results of social media depends solely on the user. If the user has the intent to misrepresent or provoke political consequences, the result will be negative. However, if the user's respect the rights and freedoms of others is equally neutral in presenting opinions and presents such data as a correct fact then precise interpretation and transparency of information will make the result will become more positive.

\section{References}

Best, J.W. (1977). Research in Education. $3^{\text {rd }}$ ed. New Jersey: Prentice-Hall.

Bloom, Benjamin S. and Others. 1956. Taxonomy of Educational Objectives. New york : David McKay Co. , Inc.

Bonk, C. J., \& Graham, C. R. (2006). The handbook of blended learning, global perspectives, local designs. Pfeiffer \& Co.

Dick, W., Carey, L. and Carey, J.O. (2001). The Systematic Design of Instruction. 5th Edition. Addison-Wesley Educational Publishers, Inc.

Fleming, M. and Levie, W. H. (1993). Instructional Message Design. 2nd Edition. New Jersy: Eaglewood Cliffs.

Gustafon, K. L. and Branch, R. M. (2002). Survey of Instructional Development Model. New York: ERIC.

Kitima Sulasonti.(2005).Knowledge Communication. Bangkok,Publisher Thammasat University.

Laddavan Suvanwak. (2012). Privacy violation behaviors of ramkhamhaeng university students in using online social networks. Theis Maeter of Arts, Ramkhamhaeng University.

Luan Saiyot (1996). Techniques for measuring learning results. Bangkok: Children's Club Publishing.

Monchai Tiantong.(2002) krawkai:Learning solution for the next education Chapter1 Develop educational techniques. 14, 43 (July-September 2545),56-66.

Office of the Council of State. Computer - Related Crime Act B.E. 2007. Retrieved July 1, 2015, form http://www.krisdika.go.th/wps/portal/general.

Surasak Kaoei. (2009). Tech research and development, electronic questionnaire creation to increase willingness in Reply and reply rate. Faculty of Education Thesis Chulalongkorn University.

Teerapat Augsuchawan. (2011). Social and violation of privacy. Thammasat University. Retrieved July 9, 2015, form http://www. publaw.net/publaw/view.aspx?id=1564. Ramkhamhaeng university.

Thai Netizen Network: Privacy International(Safeguard), Retrieved July 1, 2015. https:thainetizen.org/privacyreport2013

Voss, Andresa S. (2002). The Right to Privacy \& Assisted Reproductive Technologies: A Comparative Study of Law of Germany and the U.S. New York Law Journal of International \& Comparative Law, 2(21), 229 305.

Watkins, R., Leigh, D., \& Triner, D. (2006). Assessing readiness for E-Learning. Performance Improvement Quarterly.w. 